\title{
METODE PEMBAGIAN SINTETIK UNTUK MENGHITUNG INVERS MATRIKS VANDERMONDE DAN APLIKASINYA DALAM MEMPREDIKSI HARGA SAHAM
}

\author{
FEBY SERU \\ Program Studi S1 Matematika \\ Fakultas Matematika dan Ilmu Pengetahuan Alam, \\ Universitas Cenderawasih, Kampus Baru Jl. Kamp Wolker Waena, Jayapura, Indonesia. \\ email : febyseru.math@gmail.com
}

Diterima 4 Agustus 2021 Direvisi 15 September 2021 Dipublikasikan 21 Oktober 2021

\begin{abstract}
Abstrak. Vandermonde memiliki peranan yang penting dalam bidang matematika dan terapannya. Terdapat beberapa metode untuk menghitung invers matriks Vandermode, diantaranya metode pembagian sintetik. Metode ini memiliki kelebihan yaitu tidak memerlukan perkalian matriks maupun perhitungan determinan dalam menghitung invers matriks. Tujuan dari penelitian ini adalah mengaplikasikan metode tersebut untuk memprediksi harga saham BBRI pada bulan April dan Agustus tahun 2019. Hasil yang diperoleh adalah harga saham pada bulan April sebesar IDR 4.330 dan sebesar IDR 5.180 pada bulan Agustus.

Kata Kunci: Matriks Vandermonde, Pembagian Sintetik, Prediksi
\end{abstract}

\section{Pendahuluan}

Pada teori matriks, menentukan invers suatu matriks merupakan pembahasan yang menarik. Hal ini disebabkan karena invers matriks memiliki banyak kegunaan, salah satunya adalah untuk memecahkan sistem persamaan linear. Sistem persamaan linear ini memiliki banyak kegunaannya untuk membantu pengambilan keputusan di berbagai bidang seperti bidang ekonomi, pendidikan, manajemen, kimia, dan lain sebagainya [1].

Beberapa metode yang digunakan untuk menghitung invers matriks, yaitu metode Substitusi, Eliminasi Gauss, Eliminasi Gauss-Jordan, Matriks Adjoin, Perkalian Matriks Invers Elementer, Partisi Matriks, dan Dekomposisi Matriks LU.

Permasalahan dalam mencari invers suatu matriks biasanya berkaitan dengan ukuran matriks tersebut. Semakin besar ukuran matriks, semakin sulit mencari invers dari matriks tersebut, sehingga diperlukan rumus yang tepat untuk menentukan invers matriks [1].

Vandermonde merupakan salah satu jenis matriks yang sering muncul dalam bidang analisis numerik, matematika keuangan, statistik, geometri kurva dan teori 
kontrol [2]. Matriks Vandermonde memegang peranan penting, misalnya dalam bidang statistik, matriks Vandermonde digunakan untuk mengatasi masalah analisis deret waktu, yaitu untuk menyelesaikan persamaan stein pada proses ARMA [3]. Dalam analisis numerik, matriks Vandermonde muncul dalam interpolasi polinomial [4], dimana salah satu penerapan interpolasi polinomial adalah untuk memprediksi harga saham $[5]$.

Studi tentang pendekatan yang efisien untuk menghitung invers dari matriks Vandermonde masih menjadi topik penting dan menarik. Beberapa penelitian yang mengkaji tentang metode tersebut, diantaranya dilakukan oleh Cessa dan Eguibar [6] yang menghitung invers matriks sebagai dekomposisi dalam tiga faktor yaitu matriks diagonal, matriks segitiga atas dan matriks segitiga bawah. Oruc [7] menggunakan dekomposisi dua buah matriks yaitu matriks segitiga atas dan matriks segitiga bawah kemudian menyederhanakan rumus faktor LU untuk menghitung invers dari matriks Vandermonde. Man [9] menghitung invers dari matriks Vandermonde menggunakan pendekatan dekomposisi pecahan parsial. Pada metode ini, invers matriks Vandermonde merupakan perkalian dua buah matriks yang telah didefinisikan. Selain itu, Man [9] juga menghitung invers dari matriks vandermonde menggunakan pendekatan sederhana yaitu pembagian sintetik. Rawashdeh [2] menghitung invers dari matriks vandermonde menggunakan matriks kofaktor.

Metode yang menarik dalam menghitung invers matriks Vandermonde adalah metode pembagian sintetik yang digunakan oleh Man [9]. Kelebihan dari pendekatan ini adalah tidak memerlukan perkalian matriks, perhitungan determinan, ataupun penyelesaian sistem persamaan linear untuk menentukan entri invers dari matriks Vandermonde yang diberikan. Oleh karena itu, penelitian ini bertujuan untuk mengaplikasikan metode pembagian sintetik untuk menghitung invers matriks Vandermonde dalam memprediksi harga saham.

\section{Landasan Teori}

\subsection{Matriks Vandermonde}

Definisi 2.1. [9] Misalkan $x_{i}, 1 \leq i \leq n$ adalah himpunan bilangan yang berbeda. Matriks Vandermonde berukuran $n \times n$ didefinisikan sebagai:

$$
\left[\begin{array}{ccccc}
1 & 1 & 1 & \cdots & 1 \\
x_{1} & x_{2} & x_{3} & \cdots & x_{n} \\
x_{1}^{2} & x_{2}^{2} & x_{3}^{2} & \cdots & x_{n}^{2} \\
\vdots & \vdots & \vdots & \ddots & \vdots \\
x_{1}^{n-1} & x_{2}^{n-1} & x_{3}^{n-1} & \cdots & x_{n}^{n-1}
\end{array}\right]
$$

Karena $x_{i}, 1 \leq i \leq n$ memiliki nilai yang berbeda, maka $\operatorname{det}(V) \neq 0$, sehingga matriks Vandermonde memiliki invers.

\subsection{Interpolasi Polinomial}

Suatu proses untuk mencari dan menghitung nilai suatu fungsi berdasarkan grafik yang dibentuk dari sekumpulan titik yang diberikan disebut dengan interpolasi. 
Grafik tersebut harus melintasi semua titik dengan presisi data yang sangat tinggi. Fungsi interpolasi yang paling banyak digunakan adalah fungsi polinomial. Langkah awal dalam melakukan interpolasi polinomial adalah dengan membangun persamaan polinomial, kemudian menggunakan persamaan tersebut untuk melakukan interpolasi dari nilai yang diketahui. Nilai yang berada di dalam rentang data yang diketahui disebut dengan nilai interpolasi, sedangkan nilai yang berada di luar rentang data yang diketahui disebut dengan ekstrapolasi [11].

Definisi 2.2. [2] Polinomial berderajat $n$ secara umum dapat dituliskan sebagai berikut:

$$
f(x)=a_{0}+a_{1} x+a_{2} x^{2}+\cdots+a_{n 1} x^{n 1}+a_{n} x^{n}, a_{n} \neq 0 .
$$

dengan $a_{0}, a_{1}, \cdots, a_{n} \in R$ dan $n \in C$.

Derajat dari suatu polinomial ditentukan oleh pangkat tertinggi dari variabel pada polinomial tersebut.

Diberikan $n$ set data berpasangan $\left(x_{i}, y_{i}\right)$, fungsi interpolasi harus memenuhi:

$$
y_{i}=a_{0}+a_{1} x_{i}+a_{2} x_{i}^{2}+\cdots+a_{n 1} x_{i}^{n 1}+a_{n} x^{n}, a_{n} \neq 0 .
$$

Persamaan di atas dapat dituliskan ke dalam bentuk matriks menjadi:

$$
\left[\begin{array}{c}
y_{1} \\
y_{2} \\
\vdots \\
y_{n}
\end{array}\right]=\left[\begin{array}{ccccc}
1 & x_{1} & x_{1}^{2} & \cdots & x_{1}^{n-1} \\
1 & x_{2} & x_{2}^{2} & \cdots & x_{2}^{n-1} \\
\vdots & \vdots & \vdots & \ddots & \vdots \\
1 & x_{n} & x_{n}^{2} & \cdots & x_{n}^{n-1}
\end{array}\right]\left[\begin{array}{c}
a_{0} \\
a_{1} \\
\vdots \\
a_{n-1}
\end{array}\right]
$$

atau

$$
Y=X A
$$

Matriks $A$ diperoleh dengan persamaan:

$$
A=X^{-1} Y
$$

Perhatikan bahwa transpose dari matriks $X$ merupakan matriks Vandermonde pada Persamaan (2.1), sehingga untuk menghitung $X^{-1}$ sama dengan mencari transpose dari invers matriks Vandermonde.

\subsection{Invers Matrix Vandermonde}

Pada penelitian ini, perhitungan invers matriks Vandermonde dilakukan dengan menggunakan metode pembagian sintetik.

Definisi 2.3. [9] Didefinisikan suatu fungsi $h(x)$ dan $h_{i}(x)$ sebagai berikut:

$$
\begin{aligned}
h(x) & =\prod_{i=1}^{n}\left(x \lambda_{i}\right)=x^{n}+a_{1} x^{n-1}+\cdots+a_{n 1} x+a_{n}, \\
h_{i}(x) & =\prod_{j \neq i}\left(x-\lambda_{j}\right),
\end{aligned}
$$

untuk $1 \leq i \leq n$. 
Teorema 2.4. [9]

$$
\begin{aligned}
h_{i}(x)= & x^{n-1}+\left(\lambda_{i}+a_{1}\right) x^{n-2}+\left(\lambda_{i}^{2}+a_{1} \lambda_{i}+a_{2}\right) x^{n-3} \\
& +\cdots+\left(\lambda_{i}^{n-1}+a_{1} \lambda_{i}^{n-2}+\cdots+a_{n-2} \lambda_{i}+a_{n-1}\right) .
\end{aligned}
$$

Untuk menghitung invers matriks Vandermonde, pembagian sintetik dilakukan dengan dua tahap. Tahap pertama yaitu $h(x) \div\left(x \lambda_{i}\right)$, untuk menghitung pembilang dari tiap baris pada $V^{-1}$. Selanjutnya tahap kedua, yaitu $h_{i}(x) \div\left(x \lambda_{i}\right)$ untuk menghitung penyebut dari tiap baris pada $V^{-1}$. Jadi, setiap baris pada $V^{-1}$ dapat dihitung menggunakan dua kali pembagian sintetik. Perhitungan pembagian sintetik dilakukan dengan menggunakan metode Horner.

\subsection{Metode Horner}

Misalkan diberikan polinomial berderajat empat sebagai berikut:

$$
f(x)=a_{0}+a_{1} x+a_{2} x^{2}+a_{3} x^{3}+a_{4} x^{4}
$$

dibagi dengan $(x \lambda)$ memberikan hasil bagi $H(x)$ dengan sisa pembagian $S(x)$. Diperoleh hubungan sebagai berikut.

$$
f(x)=(x \lambda) H(x)+S(x) .
$$

Karena $f(x)$ dibagi dengan $(x \lambda)$, maka $x=\lambda$. Dengan menggunakan algoritma, nilai $f(x)$ dan sisa pembagian $S(x)$ dapat disajikan menggunakan skema sebagai berikut.

Baris pertama pada skema adalah nilai $x=\lambda$, kemudian diikuti oleh koefisienkoefisien polinomial. Koefisien-koefisien tersebut disusun dari koefisien dengan variabel yang memiliki pangkat tertinggi sampai dengan pangkat terendah [11].

$$
x=\lambda\left(\begin{array}{ccccc}
a_{4} & a_{3} & a_{2} & a_{1} & a_{0} \\
& \lambda a_{4} & \lambda a_{3}+\lambda^{2} a_{4} & \lambda a_{2}+\lambda^{2} a_{3}+\lambda^{3} a_{4} & \lambda a_{1}+\lambda^{2} a_{2}+\lambda^{3} a_{3}+\lambda^{4} a_{4} \\
\cline { 2 - 5 } & a_{3}+\lambda a_{4} & a_{2}+\lambda a_{3}+\lambda^{2} a_{4} & a_{1}+\lambda a_{2}+\lambda^{2} a_{3}+\lambda^{3} a_{4} & a_{0}+\lambda a_{1}+\lambda^{2} a_{2}+\lambda^{3} a_{3}+\lambda^{4} a_{4}
\end{array}\right.
$$

Karena $f(x)$ berderajat 4, maka $H(x)$ harus berderajat 3 sehingga diperoleh:

$$
\begin{aligned}
H(x)= & a_{4} x^{3}+\left(a_{3}+\lambda a_{4}\right) x^{2}+\left(a_{2}+\lambda a_{3}+\lambda^{2} a_{4}\right) x+\left(a_{1}+\lambda a_{2}\right. \\
& \left.+\lambda^{2} a_{3}+\lambda^{3} a_{4}\right) .
\end{aligned}
$$




\section{Pembahasan}

Studi kasus dalam penelitian ini adalah memprediksi harga saham. Data yang digunakan merupakan data bulanan saham BBRI pada tahun 2019 yang diperoleh dari https://finance.yahoo.com. Data saham tersebut disajikan pada Tabel 1. Selanjutnya akan diprediksi harga saham BBRI pada bulan April dan Agus-

Tabel 1: Harga Saham BBRI

\begin{tabular}{|c|c|}
\hline Date & Close \\
\hline $01 / 01 / 2019$ & 3.850 \\
\hline $01 / 02 / 2019$ & 3.850 \\
\hline $01 / 03 / 2019$ & 4.110 \\
\hline $01 / 06 / 2019$ & 4.360 \\
\hline $01 / 07 / 2019$ & 4.480 \\
\hline
\end{tabular}

tus tahun 2019. Pendekatan polinomial yang digunakan untuk memprediksi harga saham adalah polinomial berderajat 4 seperti pada Persamaan (2.10. Hal ini disebabkan karena data yang diketahui berjumlah 5 . Matriks persamaan polinomial dari data pada Tabel 1 adalah:

$$
Y=\left[\begin{array}{l}
3.850 \\
3.850 \\
4.110 \\
4.360 \\
4.480
\end{array}\right], X=\left[\begin{array}{ccccc}
1 & 1 & 1 & 1 & 1 \\
1 & 2 & 4 & 8 & 16 \\
1 & 3 & 9 & 27 & 81 \\
1 & 6 & 36 & 216 & 1296 \\
1 & 7 & 49 & 343 & 2401
\end{array}\right]
$$

Untuk mencari $X^{-1}$ menggunakan metode pembagian sintetik, maka matriks $X$ di-transpose terlebih dahulu sehingga menjadi matriks Vandermonde.

$$
V=X^{T}=\left[\begin{array}{ccccc}
1 & 1 & 1 & 1 & 1 \\
1 & 2 & 3 & 6 & 7 \\
1 & 4 & 9 & 36 & 49 \\
1 & 8 & 27 & 216 & 343 \\
1 & 16 & 81 & 1296 & 2401
\end{array}\right]
$$

Selanjutnya akan dicari $V^{-1}$ menggunakan metode pembagian sintetik yaitu dengan mendefinisikan terlebih dahulu fungsi $h(x)$ menggunakan Persamaan (2.7) sebagai berikut.

$$
\begin{aligned}
h(x) & =(x-1)(x-2)(x-3)(x-6)(x-7), \\
& =x^{5}-19 x^{4}+131 x^{3}-401 x^{2}+540 x-252 .
\end{aligned}
$$

Kemudian dilakukan pembagian sintetik sebanyak 2 kali. Untuk baris pertama dan kedua diperoleh perhitungan pada Gambar 1.

Diperoleh bahwa entri baris pertama dari $V^{-1}$ adalah $\left(\frac{252}{60}, \frac{-288}{60}, \frac{113}{60}, \frac{-18}{60}, \frac{1}{60}\right)$ atau $\left(\frac{21}{5}, \frac{-24}{5}, \frac{113}{60}, \frac{-3}{10}, \frac{1}{60}\right)$. Sementara entri baris kedua dari $V^{-1}$ adalah $\left(\frac{63}{10}, \frac{207}{20}, \frac{-97}{20}, \frac{17}{20}, \frac{-1}{20}\right)$. 


$$
\begin{aligned}
& x=1 \underbrace{\begin{array}{rrrrrr}
1 & -19 & 131 & -401 & 540 & -252 \\
& 1 & -18 & 113 & -288 & 252 \\
1 & -18 & 113 & -288 & 252 & 0
\end{array}} \quad \begin{array}{rrrrrrrr}
1 & -19 & 131 & -401 & 540 & -252 \\
& 1 & -17 & 97 & -207 & 126 & 0
\end{array}
\end{aligned}
$$

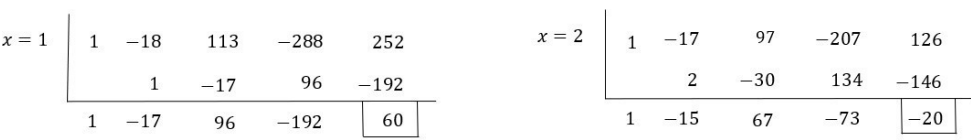

Gambar 1

Selanjutnya untuk baris ketiga dan keempat diperoleh perhitungan pada Gambar 2 .

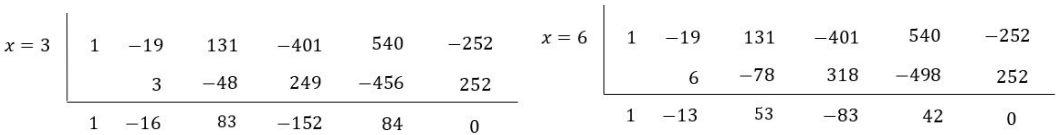

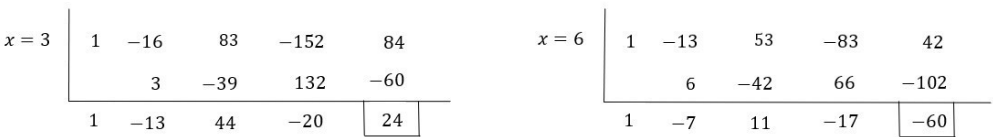

Gambar 2

Jadi, entri baris ketiga dari $V^{-1}$ adalah $\left(\frac{7}{2}, \frac{-19}{3}, \frac{83}{24}, \frac{-2}{3}, \frac{1}{24}\right)$, dan entri baris keempat adalah $\left(\frac{-7}{10}, \frac{83}{60}, \frac{-53}{60}, \frac{13}{60}, \frac{-1}{60}\right)$.

Selanjutnya untuk baris terakhir, diperoleh perhitungan pada Gambar 3.

$$
\begin{aligned}
& x=6\left[\begin{array}{rrrrrc}
1 & -19 & 131 & -401 & 540 & -252 \\
& 6 & -78 & 318 & -498 & 252 \\
\hline 1 & -13 & 53 & -83 & 42 & 0
\end{array}\right. \\
& x=6 \begin{array}{rrrrr}
1 & -13 & 53 & -83 & 42 \\
& 6 & -42 & 66 & \multicolumn{2}{c}{-102} \\
\hline 1 & -7 & 11 & -17 & -60 \\
\cline { 3 - 4 }
\end{array}
\end{aligned}
$$

Gambar 3 oleh

Jadi, entri baris terakhir dari $V^{-1}$ adalah $\left(\frac{3}{10}, \frac{-3}{5}, \frac{47}{120}, \frac{-1}{10}, \frac{1}{120}\right)$. Sehingga diper-

$$
V^{-1}=\left[\begin{array}{ccccc}
\frac{21}{5} & \frac{-24}{5} & \frac{113}{60} & \frac{-3}{60} & \frac{1}{60} \\
\frac{-63}{10} & \frac{207}{20} & \frac{-97}{20} & \frac{17}{20} & \frac{-1}{20} \\
\frac{7}{2} & \frac{-19}{3} & \frac{83}{24} & \frac{-2}{3} & \frac{1}{24} \\
\frac{-7}{10} & \frac{83}{60} & \frac{-53}{60} & \frac{13}{60} & \frac{-1}{60} \\
\frac{3}{10} & \frac{-3}{5} & \frac{47}{120} & \frac{-1}{10} & \frac{1}{120}
\end{array}\right]
$$


Setelah diperoleh invers matriks Vandermonde, selanjutnya matriks tersebut ditranspose untuk memperoleh $X^{-1}$, yaitu

$$
X^{-1}=\left(V^{-1}\right)^{T}=\left[\begin{array}{ccccc}
\frac{21}{5} & \frac{63}{10} & \frac{7}{2} & \frac{-7}{10} & \frac{3}{10} \\
\frac{-24}{5} & \frac{207}{20} & \frac{-19}{3} & \frac{83}{60} & \frac{-3}{5} \\
\frac{113}{60} & \frac{-97}{20} & \frac{83}{24} & \frac{-53}{60} & \frac{47}{120} \\
\frac{-3}{10} & \frac{17}{20} & \frac{-2}{3} & \frac{13}{60} & \frac{-1}{10} \\
\frac{1}{60} & \frac{-1}{20} & \frac{1}{24} & \frac{-1}{60} & \frac{1}{120}
\end{array}\right]
$$

elanjutnya untuk mendapatkan matriks $A$ maka digunakan Persamaan (2.6), sehingga diperoleh:

$$
A=\left[\begin{array}{c}
4.592 \\
-\frac{7.915}{6} \\
\frac{8.345}{12} \\
\frac{-755}{6} \\
\frac{91}{12}
\end{array}\right]
$$

Jadi, fungsi polinomialnya adalah:

$$
f(x)=4.592 \frac{7915}{6} x+\frac{8345}{12} x^{2}-\frac{755}{6} x^{3}+\frac{91}{12} x^{4} .
$$

Harga saham BBRI bulan April dan Agustus dapat diperoleh dengan mensubtitusikan $x=4$ dan $x=8$ ke Persamaan (3.7), sehingga diperoleh harga saham BBRI pada bulan April sebesar IDR 4.330 dan bulan Agustus sebesar IDR 5.180.

\section{Kesimpulan}

Pasa perhitungan prediksi harga saham BBRI menggunakan metode pembagian sintetik, diperoleh harga saham BBRI pada bulan April adalah sebesar IDR 4.330 dan sebesar IDR 5.180 untuk bulan Agustus.

\section{Daftar Pustaka}

[1] Marzuki, C. C., Aryani, F., 2019, Invers Matriks Toeplitz Bentuk Khusus Menggunakan Metode Adjoin, Jurnal Sains Matematika dan Statistika, 5(1) : 58 67

[2] Rawashdeh, E., 2019, A Simple Method for Finding The Inverse Matrix of Vandermonde Matrix, MATEMATICKI VESNIK, 3(71) : 207 - 213

[3] Klein, A., Spreij, P., 2003, Some Results on Vandermonde Matrices with an Application to Time Series Analysis, SIAM Journal Matrix Analysis and Applications, 25(1) : 213 - 223

[4] Eisinberg, A., Fedele, G., 2006, On The Inversion of The Vandermonde Matrix, ELSEVIER Applied Mathematics and Computation, 174(2) : 1384 - 1397

[5] Pangruruk, F. A., Barus, S. P., Siregar, B., 2020, Peramalan Harga Saham Tutup dengan Metode Interpolasi Polinom Lagrange, Seminar Nasional VARIANSI, $118-126$

[6] Cessa, H. M., Eguibar, F. S., 2011, Inverse of the Vandermonde and Vandermonde Confluent Matrices, Applied Mathematics and Information Sciences, 5(3) : $361-366$ 
[7] Oruc, H., 2007, L U Factorization of the Vandermonde Matrix and its Applications, ELSEVIER Applied Mathematics Letters, 20(9) : 982 - 987

[8] Man, Y. K., 2015, On The Inversion of Vandermonde Matrix Via Partial Fraction Decomposotion , IAENG Transaction on Engineering Sciences, edited by S. Ao, H.S. Chan, H. Katagiri and L. Xu, World Scientific, Singapore, 57 - 66

[9] Man, Y. K., 2018, On Computing the Inverse of Vandermonde Matrix, Advances in Theoretical and Applied Mathematics, 13(1) : 15 - 21

[10] Astuti, L. W., Sudarwanto, Ambarwati, L., 2018, Perbandingan Metode Lagrange dan Metode Newton pada Interpolasi Polinomial dalam Mengestimasi Harga Saham, Jurnal Matematika Terapan 2(1) : 25 - 35

[11] Ahmand, M., 2016, Upaya Meningkatkan Prestasi Belajar Siswa dalam Menyelesaikan Pembagian Suku Banyak dengan Metode Pembagian Sintetik di Kelas XI IPA Semester IV Taman Madya (SMA) Tamansiswa Medan T.P 2009/2010, Jurnal Education and Development STKIP Tapanuli Selatan,1(4) : 32 - 40 